\title{
Research Article \\ Lesions of nasal cavity, paranasal sinuses and nasopharynx - An analysis over 3 years at a tertiary care setting
}

De Alwis ASR ${ }^{1}$ (iD) , De Silva $\mathrm{HMSS}^{2}$, De Silva WHR ${ }^{1}$, Jayasuriya $\mathrm{C}^{3}$

${ }^{1}$ Registrar in ENT, National Hospital of Sri lanka (NHSL), Sri Lanka

${ }^{2}$ Registrar in General Surgery, National Hospital of Sri lanka (NHSL), Sri Lanka

${ }^{3}$ Consultant ENT and Head \& Neck Surgeon, National Hospital of Sri lanka (NHSL), Sri Lanka

\begin{abstract}
\section{Objective}

Lesions involving nasal cavity(NC), paranasal sinuses(PNS) and nasopharynx consists of a wide variety of inflammatory, non-neoplastic and neoplastic lesions. Even though they are common in Sri Lanka proper data is scarce. The aim of this study is to determine various histopathological patterns of NC, PNS and nasopharyngeal lesions, their relative distribution with regard to age and sex in our setting.

\section{Methodology}

A retrospective analytical study was carried out in all patients who underwent biopsies of the above lesions presented to ENT unit at National Hospital of Sri Lanka from 1.1.2015 to 31.12.2017.

\section{Results}

From 238 patients who underwent biopsies, the commonest site was the NC (51.06\%) followed by the PNS (43.9\%). Male to female ratio was 1.38:1. 79.8\% were non-neoplastic, from which $88.9 \%$ were inflammatory and $7.3 \%$ were fungal, where mucormycosis and rhinosporidiosis being the commonest. Out of the neoplastic conditions $(20.8 \%), 54.1 \%$ were benign, with inverted papilloma being the commonest $(42.3 \%)$, commonly seen in 6th and 7th decades with a male predominance, followed by angiofibroma $(15.3 \%)$. Squamous cell carcinoma is the commonest malignancy (40.9\%), common in 7 th and 8 th decades with a male predominance, followed by adenocarcinoma (18.18\%), adenoid cystic carcinoma (9\%) and non- Hodgkin's B cell lymphoma (9\%).

\section{Conclusion}

Internationally benign and malignant neoplasms are more common in 4 to 5 th decades and 5-6th decades respectively. But in our study both benign and malignant neoplasms were found approximately two decades later in life. This may be due to the late presentation hence we recommend a thorough ENT examination at the earliest presentation of nasal symptoms.
\end{abstract}

Key words: nasal cavity, paranasal sinuses, histopathology, neoplastic

Copyright: (C) 2020 De Alwis ASR et al.

This is an open access article distributed under the Creative Commons Attribution License (CC-BY) @ @ (1) This license lets others distribute, remix, tweak, and build upon the work, even commercially, as long as they credit the original author for the creation.

Funding: None

Competing interest: None

Correspondence: De Alwis ASR (2shashini@gmail.com)

Accepted Date $: 6^{\text {th }}$ Feb 2020

Published Date : $22^{\text {nd }}$ Feb 2020 


\section{Introduction}

Lesions involving nasal cavity(NC), paranasal sinuses(PNS) and nasopharynx are routinely encountered in the ENT clinic. They have a diverse group of pathologies and consists of a wide variety of inflammatory, non-neoplastic and neoplastic conditions. Since they are difficult to be differentiated clinically, histological diagnosis is the mainstay of diagnosis.(Garg 2014) These lesions can present with nasal symptoms such as blocked nose, epistaxis, rhinorrhea, or with orbital symptoms like diplopia, proptosis or generalized symptoms like headache and malaise.(Jonathan Ray Newton 2008) The aim of the study is to determine various histopathological patterns of NC, PNS and nasopharyngeal lesions, their relative distribution with regard to age and sex and compare the incidences.

\section{Methodology}

A retrospective study was carried out on patients who presented to ENT clinic at National Hospital of Sri lanka, with lesions in the NC, PNS, and nasopharynx, over a period of 3 years. (from 1.1.2015 to 31.12.2017) All patients underwent a thorough ENT examination and with the informed consent, relevant biopsies were taken and submitted for histopathological examination by the Department of Histopathology, NHSL. All specimens were fixed in 10\% formalin and processed routinely. Required sections were stained with Hematoxylin and eosin. Stain and staining with Periodic acid schiff and Giemsa stains were done wherever necessary.

\section{Results and Discussion}

Total number of 238 patients presented with lesion in the NC, PNS and nasopharynx during the period of three years. The incidence of nasal, PNS and nasopharyngeal lesions is 79.3 cases per year. This is higher than the incidence observed by M Kulkarni et al. which is 16.7 and 34.3 by Khan et al. This may be due to increased prevalence of asthma and allergic rhinitis in Sri lanka. Males are commonly affected than females having a male: female ratio of $1.38: 1$, which complies with international data.

The commonest site was the $\mathrm{NC}(51.06 \%$ - 144 cases) followed by the PNS(43.9\% - 124 cases) and nasopharynx $(4.9 \%$ - 14 cases $)$.Similar pattern was observed by Khan et al. where $74.19 \%$ of polyps was seen in the nasal cavity and only $25.81 \%$ in the sinuses. Maxillary sinus was involved mainly $(56 \%)$, next being ethmoid (30.6\%) and Sphenoid (7.25\%) .This complies with observations made by (Iemma et al. 1992)

Most of the lesions were non neoplastic $79.8 \%$ and only $20.8 \%$ were neoplastic, similar to data published by M Kulkarni et al. 2012 with $86 \%$ and $14 \%$ respectively. $88.9 \%$ of the non-neoplastic lesions were inflammatory, $7.3 \%$ were fungal, $1.9 \%$ were pyogenic granuloma and $1.9 \%$ allergic polyps. 
Figure 1. Prevalence of non- neoplastic conditions of Nasal cavity, Paranasal sinuses and Nasopharynx

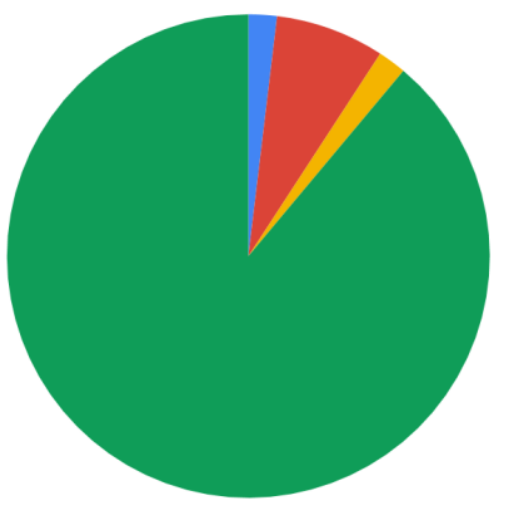

\author{
- Allergic polyps \\ - Fungal \\ - Pyogenic granuloma \\ Inflammatory
}

In Asian countries Rhinosporidiosis is known to be endemic ${ }^{8}$. Even though (Kumari M.K. \& K. 2013) reported the incidence of rhinosporidiosis as $24 \%{ }^{7}$ in our study, it was $7.1 \%$. Mucormycosis was present in $21.4 \%$ of the fungal lesions. This is higher than the incidence reported by (Petrikkos et al. 2012), which was $8.3 \%-13 \%$ of all fungal infections. Mucormycosis which was previously known as zygomycosis, is caused by infection with fungi in the order Mucorales and is an emerging healthcare problem in south east asia. (Chakrabarti \& Dhaliwal 2013) It is known as the third most common invasive mycosis in patients with haematological and allogeneic stem cell transplantation, where candidiasis and aspergillosis being the first and the second respectively. Also it is common in patients with uncontrolled diabetes mellitus.(Petrikkos et al. 2012)

Among the neoplastic lesions 54.1\% was benign and $45.8 \%$ was malignant, but (M Kulkarni et al. 2012) has observed $81.25 \%$ benign lesions in his study. Among the benign lesions inverted papilloma is the commonest (42.3\%) commonly seen in 6th and 7th decades with a male predominance. Even though (Khan et al. 2006) too has observed a male predominance, it was common in 3rd decade. This can be due to late presentation in our setting. Angiofibroma is seen in $15.38 \%$ of patients, and is comparatively less than the incidence observed by (Khan et al. 2006) . (42.85\%). The other benign lesions include neurofibroma, haemangioma squamous papilloma and epidermoid cyst.

From the malignant lesions in NC,PNS and nasopharynx Squamous cell carcinoma is the commonest (40.9\%).(Panchal et al. 2005) reported 53\% of squamous cell carcinoma amongst their malignant epithelial tumors and (M Kulkarni et al. 2012) 50\%. This is followed by adenocarcinoma (18.18\%), adenoid cystic carcinoma(9\%) and non- Hodgkin's B cell lymphoma(9\%), common in 7th and 8th decades with a male predominance, which was a decade older than for benign lesions. According to international data it is common in 5th and 6th decades (M Kulkarni et al. 2012; Anon n.d.) 
Table 1 : Distribution of malignant lesions of Nasal Cavity, PNS and nasopharynx

\begin{tabular}{|l|l|}
\hline Malignant lesion & No (\% of cases) \\
\hline Squamous Cell Carcinoma & $9(40.9 \%)$ \\
\hline Adenocarcinoma & $4(18.8 \%)$ \\
\hline Adenoid cystic carcinoma & $2(9 \%)$ \\
\hline Hodgkin's Lymphoma & $2(9 \%)$ \\
\hline Small cell Carcinoma & $1(4.46 \%)$ \\
\hline Olfactory neuroblastoma & $1(4.46 \%)$ \\
\hline Plasmacytoma & $1(4.46 \%)$ \\
\hline Myeloid sarcoma & $1(4.46 \%)$ \\
\hline Sinonasal undifferentiated carcinoma & $1(4.46 \%)$ \\
\hline
\end{tabular}

\section{Conclusion}

Most of the lesions in NC, PNS and Nasopharynx are non-neoplastic. Increase incidence of cases per year which can be due to increased prevalence of asthma and allergic rhinitis

Malignant lesions are common in 7 th and 8 th decades with a male predominance, which was a decade older than for benign lesions (6th and 7th decade). Internationally benign and malignant neoplasms are more common in 4-5th decades and 5-6th decades respectively

This may be due to the late presentation hence we recommend a thorough ENT examination at the earliest presentation of nasal symptoms 


\section{References}

1. Anon, Key Statistics About Nasal Cavity and Paranasal Sinus Cancers. Available at: https://www.cancer.org/cancer/nasal-cavity-and-paranasal-sinus-cancer/about/key-statistics.html [Accessed July 3, 2018].

2. Chakrabarti, A. \& Dhaliwal, M., 2013. Epidemiology of Mucormycosis in India. Current fungal infection reports, 7(4), pp.287-292. https://doi.org/10.1007/s12281-013-0152-z

3. Garg, D., 2014. Clinico-pathological Study of Space Occupying Lesions of Nasal Cavity, Paranasal Sinuses and Nasopharynx. Journal of clinical and diagnostic research: JCDR. Available at: http://dx.doi.org/10.7860/jcdr/2014/10662.5150. https://doi.org/10.7860/JCDR/2014/10662.5150 PMid:25584226 PMCid:PMC4290245

4. Iemma, M., Maurer, J. \& Mann, W., 1992. [The incidence and location of inflammatory paranasal sinus lesions in CT]. Acta otorhinolaryngologica Italica: organo ufficiale della Societa italiana di otorinolaringologia e chirurgia cervico-facciale, 12(2), pp.135-142.

5. Jonathan Ray Newton, K.W.A.-S., 2008. A review of nasal polyposis. Therapeutics and clinical risk management, 4(2), p.507.

https://doi.org/10.2147/TCRM.S2379

PMid:18728843 PMCid:PMC2504067

6. Khan, N. et al., 2006. Masses of nasal cavity, paranasal sinuses and nasopharynx: A clinicopathological study. Indian journal of otolaryngology and head and neck surgery: official publication of the Association of Otolaryngologists of India, 58(3), pp.259-263.

7. Kumari M.K., K. \& K., K.K.M., 2013. Polypoidal Lesions in the Nasal Cavity. Journal of clinical and diagnostic research: JCDR. Available at: http://dx.doi.org/10.7860/jcdr/2013/4718.3025.

https://doi.org/10.7860/JCDR/2013/4718.3025

PMid:23905098 PMCid:PMC3708193

8. Makannavar, J.H. \& Chavan, S.S., 2001. Rhinosporidiosis--a clinicopathological study of 34 cases. Indian journal of pathology \& microbiology, 44(1), pp.17-21.

9. M Kulkarni, A. et al., 2012. Histopathological study of lesions of nose and paranasal sinuses. Indian journal of otolaryngology and head and neck surgery: official publication of the Association of Otolaryngologists of India, 64(3), pp.275-279. https://doi.org/10.1007/s12070-011-0286-7 PMid:23998035 PMCid:PMC3431534

10. Panchal, L. et al., 2005. Sino-nasal epithelial tumours: a pathological study of 69 cases. Journal of postgraduate medicine, 51(1), pp.30-4; discussion 34-5.

11. Petrikkos, G. et al., 2012. Epidemiology and clinical manifestations of mucormycosis. Clinical infectious diseases: an official publication of the Infectious Diseases Society of America, 54 Suppl 1, pp.S23-34.

https://doi.org/10.1093/cid/cir866

PMid:22247442 